\title{
Technologies Protecting the Environment in Urban Areas
}

\author{
Kostadin Kostadinov ${ }^{1, *}$, Stoyan Filipov ${ }^{1}$, Radoslav Chipilski ${ }^{2}$, and Nadezhda Shopova ${ }^{3}$ \\ ${ }^{1}$ Agricultural University - Plovdiv, AU, 12 Blvd Mendeleev, 4000 Plovdiv, Bulgaria \\ ${ }^{2}$ Institute of Plant Genetic Resources "K. Malkov," 2 Str. Drujba, 4122, Sadovo, Bulgaria \\ ${ }^{3}$ Climate, Atmosphere and Water Research Institute at Bulgarian Academy of Sciences (CAWRI-BAS), 66, Blvd Tzarigradsko \\ chaussee, 1784 Sofia, Bulgaria
}

\begin{abstract}
Global warming is the leading cause of the extreme meteorological events increase in the last three decades. Increase of annual average air temperature and temperature values during winter and early spring has been recorded in comparison to the (1961-1990) referent period in Plovdiv region. The lettuce development was researched in a greenhouse in the Agricultural University- Plovdiv. During the lettuce growth six different variants were used: no fertilizer, one chemical, and four organic fertilizers. The effect of the different organic fertilizers was studied through specific physiological parameters and productivity. This paper analyzed changes in functional activity of the plant photosynthetic apparatus and productivity of variants with different fertilizers in an unheated greenhouse. The ratio between photosynthetic active radiation (PAR) and quantum yield (qY-Fv/Fm) of PS II was determined to be more optimal in darkadapted leaves for the organic fertilizer variants, compared to the no fertilizer variant. The lower and significant difference was observed in the values of the minimal fluorescence Fo in reaction centers of PS II after the dark-adaptation of leaves for organic fertilizer variants compared to the no fertilizer variant. Higher values of chlorophyll content index (CCI) were estimated for organic and chemical fertilizers compared to the no fertilizer variant. All variants fertilized with organic and biofertilizers comply with the quality standard from the beginning to the end of harvesting.
\end{abstract}

\section{Introduction}

In recent years, with the intensification of extreme phenomena of meteorological origin, the advancement of agricultural science and the desire of people to produce qualitative and safe food with minimal risk to the environment, biological farming technologies have aroused scientific interest. Production without mineral fertilizers is important for the environment protection, for the balance and fertility of the soil, as well as for human health. The lettuce is a vegetable, intended only for fresh consumption, which requires good taste and purity of production. Vitamins A, B, C, D, and E can be found in the leaves of the species [1]. The vegetable is one of the main components from the dietary menu and the table in Bulgaria. The resistance of the species to low temperatures and the duration of the period up to their typical leaf mass reached growth stage make it preferred both for autumn-winter production in unheated facilities and for early spring cultivation. Both the higher temperatures and the changes in the humidification conditions in the country $[2,3$,$] and the studied area ([4],$ registered in the recent decades, affect the specific meteorological conditions, the growth and development of the different production [5] and types of lettuces. It is necessary to specify the varieties and the fertilization. Therefore, an experiment in polyethylene greenhouses with a type of lettuce was set (type Lollo rosso, variety
Tuska) with six different variants of mineral, organic and biological fertilization, namely: no fertilization; mineral fertilization and fertilization with four organic and biofertilizers. There are studies on the interaction of different factors on the physiological status of plants [6]. The physiological condition of plants and effect of various stressful factors thereon have been studied using chlorophyll fluorescence properties by many researchers $[7,8$,$] . Chlorophyll fluorescence is a non-invasive$ measurement of photosystem II (PSII) activity and is a commonly used technique in plant physiology. The sensitivity of PSII activity to abiotic and biotic factors has made this a key technique not only for understanding the photosynthetic mechanisms but also as a broader indicator of how plants respond to environmental change [9]. The fluorescence is emitted mainly from chlorophyll $a$ of PSII and reflects the primary processes of photosynthesis by light absorption, distribution and transfer of excitation energy and photochemical reactions in PSII. Because of the functional relation of PSII with other components of the photosynthetic apparatus of the chlorophyll fluorescence, it is seen as a proxy for the state of the integral photosynthetic process and the plant organism as a whole [10]. Chlorophyll fluorescence, among others, has been satisfactorily used for monitoring leaf health status in lamb's lettuce [11] and storage potential of iceberg lettuce [12]. The CCM (Chlorophyll Content Meter) 200 plus is useful for improving nitrogen

* Corresponding author: kostadinov8888@gmail.com 
and fertilizer management, and is ideal for crop stress, leaf senescence, plant breeding, health determination, and other studies. Furthermore, the affordability and ease of use make it an exceptional teaching tool for botany and plant science courses $[13,14]$. The aim of the present study was to monitor the reaction of the leafy lettuce (type Lollo Rosso, variety Tuska) to six different fertilization variants by analyzing the temperature conditions and measuring the main parameters of productivity and photosynthetic activity.

\section{Material and Methods}

The experiment was conducted on the experimental field of the Agricultural University of Plovdiv in 2018-2020 in unheated greenhouses on alluvial meadow soil (Mollic fluvisol, FAO 2006). The soil texture is sandy clay loam to clay loam, despite the small amount of total carbonates $(2-3 \%)$, the soil reaction is slightly alkaline $\mathrm{pH}_{(\mathrm{H} 2 \mathrm{O})}-7.7-$ 8.0 [15]. The same authors found a high amount of exchange bases $\left(\mathrm{Ca}^{2+}+\mathrm{Mg}^{2+}-20-30 \mathrm{meq} / 100 \mathrm{~g}\right.$ soil $)$ in the composition of the soil sorption complex, and a low content of nitrogen, phosphorus and potassium. The importance of the organic matter of the soil for its fertility is indisputable. However, the nitrogen bound in the organic matter remains hidden in this indicator. The nitrogen in organic form, which is over $95.0 \%$ of total soil nitrogen is the basis of soil fertility. Organic nitrogen is the source that supports the plants throughout the growing season and ensures an even supply of nitrogen to the plants. The active fraction of soil nitrogen varies with different soil types and depends on a number of factors degree of cultivation, field history (previous crops in the crop rotation, fertilization system), biotic and abiotic soil characteristics and some environmental factors, mainly temperature and humidity. The red lettuce plants (type Lollo Rosso, variety Tuska) were planted on $8^{\text {th }}$ of November in polyethylene greenhouses in 4 rows according to the scheme $70+30+30+30 / 30 \mathrm{~cm}$ with a profile of the soil surface a high level bed $(100+60 \mathrm{~cm})$ The experiment was based on the block method with four repetitions, using 28 plants per repetition, and a plot size of $3.36 \mathrm{~m}^{2}$. Organic seeds were provided for seedling production using container technology with 150-hole Styrofoam boards with mixture in the following combination $-80.0 \%$ Perlite : $20.0 \%$ Lumbricompost as volume parts for bioproduction of seedlings [16]. Several variants were tested: 1. Control (non-fertilization); 2. NPK (mineral fertilization); 3. Italpollina (organic fertilizer); 4. Arkobaleno (organic fertilizer); 5. LC (Lumbricompost- organic fertilizer) and 6. Ekoprop NX (bio fertilizer). The granular fertilizers were introduced as basic fertilization, with soil pre-transplantation at the following norms: $\mathrm{N}-12.5 \mathrm{~kg} / \mathrm{da}, \mathrm{P}_{2} \mathrm{O}_{5}-1.25 \mathrm{~kg} / \mathrm{da},+\mathrm{K}_{2} \mathrm{O}-$ $4.75 \mathrm{~kg} / \mathrm{da}$, Italpollina-25 kg/da, Arkobaleno - $100 \mathrm{~kg} / \mathrm{da}$, and Lumbricompost - $400 \mathrm{l} / \mathrm{da}$. The liquid bio fertilizer Ekoprop NX was applied by double treatment in a dose of $100 \mathrm{~g} / \mathrm{da}$, before planting - in the 5th leaf seedling phase, and 10 days later on, after the adaptation to the soil. The organic fertilizers are introduced into the soil before the last tillage and before planting the seedlings. The biometric measurements were performed from the beginning of the harvest at an interval of 7 days.

\subsection{Experimental setting}

Meteorological observations from Plovdiv AU (Agricultural University) station $\left(42^{\circ} 14^{\prime} \mathrm{N}, 24^{\circ} 75^{\prime} \mathrm{E}\right.$ and $162 \mathrm{~m}$ above sea level) were used for the outdoor temperature analysis. The data were collected according to the recommendations of the WMO (World Meteorological Organization) and are also comparable with the climatic norm for the region. In greenhouse conditions, the air temperature was recorded by means of a weather station Meteobot@ Pro (https://meteobot.com/). The active temperatures were calculated as the sum $\Sigma^{\circ} \mathrm{C}$ $=\mathrm{T}-\mathrm{Tb}$, where $\mathrm{T}-\mathrm{Tb}$ is taken 0 when $\mathrm{T}<\mathrm{Tb}$ and $\mathrm{T}$ is taken as $\mathrm{Tu}$ when $\mathrm{T}>\mathrm{Tb}[17]$.

\subsection{Chlorophyll fluorescence imaging}

The Chlorophyll fluorescence of the lettuce leaves was measured using a portable device PAR-FluorPen FP 110/D manufactured by Photon Systems Instruments Ltd., Czech Republic. The fluorescence measurement protocol uses short $(30 \mu \mathrm{s})$ measuring flashes to measure zero level fluorescence $\left(F_{0}\right)$ followed by a strong saturating flash (duration $0.8 \mathrm{~s}$, intensity about $3000 \mu \mathrm{mol} \mathrm{m}-2 \mathrm{~s}-1$ ) to measure the maximum fluorescence $(F \mathrm{~m})$. Three strong flashes of saturating light probed the effective quantum yield (Qy) of PSII during the actinic light exposure [18, 19]. Light Meter for direct digital readouts of Photosynthetically Active Radiation (PAR) in the range from 400 to $700 \mathrm{~nm}$, the span in which plants use energy during photosynthesis. PAR is measured as Photosynthetic Photon Flux Density (PPFD), which is indicated by units of quanta (photons) per unit time per unit surface area. The chlorophyll fluorescence transients were measured on the same day in the morning. The measurements were performed from the beginning of the harvest at an interval of 7 days. The nine leaves from each variant were dark adapted for about $30 \mathrm{~min}$ by detachable leaf-clips prior each measurement. The numeric value of each parameter $\left(\mathrm{Fv} / \mathrm{Fm}, \mathrm{F}_{\mathrm{o}}\right.$, PAR) was determined by integrating it over the measured leaf area.

\subsection{Physiological estimate of the chlorophyll content index (CCl)}

The Chlorophyll content index of the leaves was measured using a portable apparatus CCM 200 plus (Chlorophyll Content Meter) manufactured by Optisciences, Inc., NH, USA. The physiological assessment was carried out in vivo on the field. The measurements were performed from the beginning of the harvest at an interval of 7 days. The measurements from the central part of 20 leaves were taken for each variant (in each of the repetitions).

\subsection{Statistical evaluation of the results}


To prove differences in the mean values, a one-way ANOVA analysis of variance was performed within the variants of each variety, followed by LSD analysis by means of a Fisher's test. Mathematical processing and statistical analysis were made and visualized using Microsoft ${ }^{\circledR}$ Office products.

\section{Results and Discussion}

\subsection{Thermal conditions}

The observed climatic fluctuations in the study area during the last three decades have influenced the meteorological conditions of growth and development of lettuce in the open air and are related to the temperature in unheated greenhouses (Table 1). As with any plant species, so with lettuce, 3 cardinal temperature points are defined - minimum, maximum and optimal value. According to some Bulgarian and foreign authors [20, 21] the optimal temperature for lettuce development is 16.0 $18.0^{\circ} \mathrm{C}$ and its development occurs in the range $7.0^{\circ} \mathrm{C}-24$. $0^{\circ} \mathrm{C}$ [22]. [23] indicates the temperature values $12.0^{\circ} \mathrm{C}$ $21.0^{\circ} \mathrm{C}$ as the limits for optimal lettuce development. Lettuce is a cold-resistant crop, with a biological minimum of development in the range $3.0^{\circ} \mathrm{C}-5.0^{\circ} \mathrm{C}$ according to the findings of the authors as follows: from $5.0^{\circ} \mathrm{C}[24], 4.0^{\circ} \mathrm{C}[25,26]$ mentioning that development is possible at a lower temperature $\mathrm{Tb}=3.0^{\circ} \mathrm{C}$.

Table 1. Average monthly outdoor air temperature and deviation from the climatic norm during the period of development of lettuce type Lollo Rosso, variety Tuska

\begin{tabular}{|l|l|l|l|l|}
\hline Months & $\begin{array}{c}\text { Average } \\
\mathbf{t}^{\mathbf{0}} \mathbf{C} \\
\mathbf{2 0 1 8 / 2 0 1 9}\end{array}$ & $\begin{array}{c}\Delta \mathbf{t}^{\mathbf{0}} \mathbf{C} \\
\mathbf{( 1 9 6 1 -} \\
\mathbf{1 9 9 0 )}\end{array}$ & $\begin{array}{c}\text { Average } \\
\mathbf{t}^{\mathbf{0}} \mathbf{C} \\
\mathbf{2 0 1 9 / 2 0 2 0}\end{array}$ & $\begin{array}{c}\Delta \mathbf{t}^{\mathbf{0}} \mathbf{C} \\
(\mathbf{1 9 6 1 -} \\
\mathbf{1 9 9 0 )}\end{array}$ \\
\hline November & 7.3 & +0.3 & 10.8 & +3.8 \\
\hline December & 2.9 & +0.5 & 4.4 & +2.0 \\
\hline January & 2.6 & +2.3 & 6.4 & +3.2 \\
\hline February & 3.8 & +1.0 & 8.9 & +3.6 \\
\hline March & 10.6 & +3.8 & 11.5 & +2.1 \\
\hline April & 12.6 & +0.4 & 17.6 & -0.7 \\
\hline
\end{tabular}

During the two years of the experiment, the development of the lettuce in unheated greenhouses from planting to harvest took place during the period November -April. The temperature conditions in unheated greenhouses (Figures 1 and 2), with a film thickness of $0.20 \mathrm{~mm}$ were determined by the excessive outdoor conditions (Table 1). In 2018/2019 all monthly values had positive deviations from the climatic norm 1961-1990 - between $0.4^{\circ} \mathrm{C}$ in April and $3.8^{\circ} \mathrm{C}$ in March. The autumn-winter period of 2019/2020 was extremely warm as three of the months had a deviation of $>3.0$ (November $3.8^{\circ} \mathrm{C}$; January $3.2^{\circ} \mathrm{C}$; February $3.6^{\circ} \mathrm{C}$ ). The coldest month was April, when the last harvest of the plants was reported with $\Delta \mathrm{t}^{0}=\left(-0.7^{\circ} \mathrm{C}\right)$. The lettuces variety Tuska were planted with an average weight of their ground part of $-2.59 \mathrm{~g}$, in the phenophase of their $6^{\text {th }}$ leaf formed according to $\mathrm{BBCH}$ [27]. In the first year, the months of December, January and February were with an average temperature below the biological minimum of the species, and in the second year only December was with average values below $5.0{ }^{\circ} \mathrm{C}-4.4^{\circ} \mathrm{C}$. The data show that compared to the conditions outside, the average temperature in the greenhouse is higher by $2.5^{\circ} \mathrm{C}$. For the whole period (149 days), the days with temperatures below the biological minimum $5.0^{\circ} \mathrm{C}$ [24] marked with a green dotted line in the diagrams, were reduced from 58 outside to 25 inside the greenhouse (Figures 1 and 2). The collected active amount/sum $\left(\Sigma A t^{\circ} \mathrm{C}\right)$ for the vegetation period $(124$ days $)$ is $\left(\Sigma \mathrm{At}^{\circ} \mathrm{C}\right)=1267^{\circ} \mathrm{C}$. The effective temperature sum $\left(\Sigma \mathrm{Eft}{ }^{\circ} \mathrm{C}\right)$ from planting the lettuce to its last harvest in a polyethylene greenhouse is $\Sigma \mathrm{Eft}{ }^{\circ} \mathrm{C}=647^{\circ} \mathrm{C}$. For the period 21 March - 4 April of the second year, there were only two days with temperatures below the biological minimum, thus the collected active temperatures from the first to the last harvest are $\left(\sum \mathrm{At}^{\circ} \mathrm{C}\right)$ $=137^{\circ} \mathrm{C}$, and the effective ones $\left(\Sigma \mathrm{Eft}{ }^{\circ} \mathrm{C}=72.0^{\circ} \mathrm{C}\right.$. The additionally collected air temperature levels between the initial and final measurement showed the smallest increase in fresh mass weight in the case of using NPK (70.92g), and the largest - when Ekoprop was used $(151.77 \mathrm{~g})$ while for the other variants it was as it follows: Control - 99.9g; Italpollina - 93.17g; Arcobaleno 109.08g; LC Ekoprop NX - 132.42g (Table 2). The number of whole leaves increased between 4 (Control; Arkobaleno) and 5 in the conventionally and organically fertilized variants. With respect to the parameter leaf rosette diameter, except for the case of using Arkobaleno, the positive $\Delta \mathrm{cm}$ in the organically fertilized variants was greater than in the Control variant (Table 2).

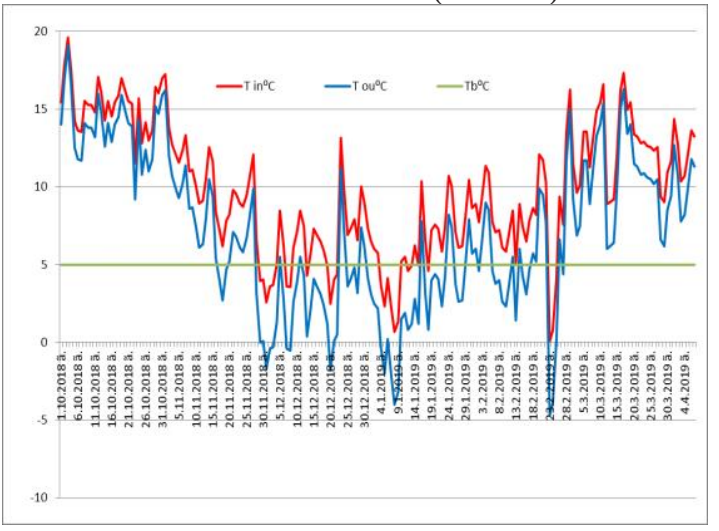

Fig. 1. Average daily temperature in an unheated greenhouse and outdoors November - April 2018/2019

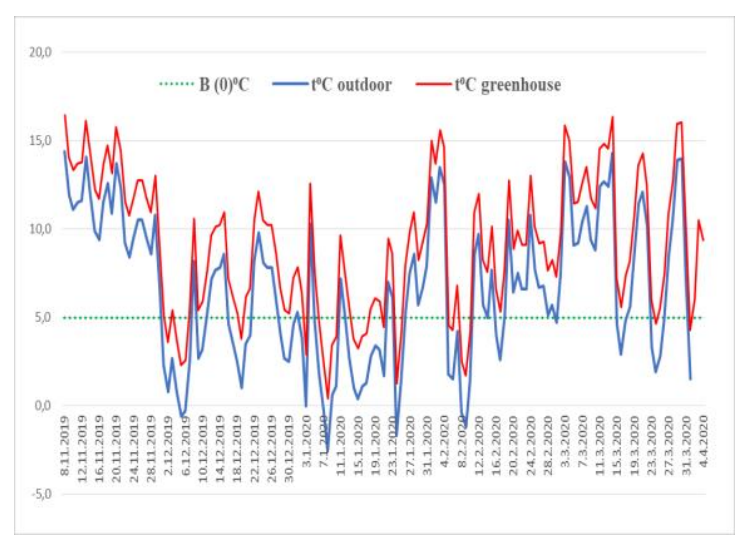

Fig. 2. Average daily temperature in an unheated greenhouse and outdoors November - April 2019/2020 
Table 2. Vegetative and morphological behavior of the lettuce type Lollo Rosso, variety Tuska, deviation $\Delta$ between the initial and final measurement.

\begin{tabular}{|c|c|c|c|c|c|c|}
\hline Index & Control & NPK & Italpollina & Arkobaleno & LC & Ekoprop NX \\
\hline $\begin{array}{c}\text { leaf rosette } \\
\text { diameter } \Delta \text { cm. }\end{array}$ & 4.65 & 7.20 & 5.00 & 4.33 & 5.82 & 5.27 \\
\hline leaves, number $\Delta$ & 4 & 5 & 5 & 4 & 5 & 5 \\
\hline $\begin{array}{c}\text { fresh mass of the } \\
\text { whole plant, } \Delta \mathbf{g .}\end{array}$ & 99.91 & 70.92 & 93.17 & 109.08 & 132.42 & 151.77 \\
\hline
\end{tabular}

\subsection{Physiological parameters}

The mean value of the initial fluorescence $\left(\mathrm{F}_{0}\right)$ of the oxidized reaction centers of PSII was highest in the control and mineral fertilization variant, and lowest in the Arkobaleno and LC organic and biological fertilization variants (Table 3). Significant differences in the average values of the different fertilization variants were calculated for this indicator, with the highest level of significance up to $\mathrm{p}=0.001$ between the biological variants Arkobaleno and LC and the control variant. In relation to the studies of $[28,29]$, who believe that a higher value of $F_{0}$ is associated with high temperature stress, we can conclude that the temperature conditions in the greenhouse lead to a more pronounced stress response in the unfertilized control plants. For parameter Qy (Fv/Fm), a statistically significant lowest value was registered for the control plants -0.768 and a highest value was read for the mineral fertilization variant 0.798. Higher values were also reported for the variants with organic and biological fertilization compared to the control. The highest value was registered for the variant of fertilization with Arkobaleno - 0.786 (Table 3).

The comparative characteristic made by dates of measurements shows the largest difference between the unfertilized variant and the variants with organic and biofertilizers on the first measurement date. The mean value of Qy for all variants in this study indicates the presence of moderate stress in the photosynthetic activity of the plants, most pronounced in the control variant. It was confirmed from the average value of the ratio $\mathrm{Fv} / \mathrm{Fm}$ or the quantum yield Qy of the different variants, which was close to the normal for healthy leaves - 0.83 [30]. The measured photosynthetically active radiation (PAR) is higher on the first two dates, which is associated with the higher daily temperatures and the increased solar radiation compared to the atmospheric conditions during the third reporting date. The higher PAR values on the first two dates are associated with a lower Qy value, and this reduction should not be associated with photoinhibition due to low PAR values. The most optimal ratio between the values of PAR and Qy was reported for Ekoprop, as well as for the variant with mineral fertilization (Table 3 ).

Table 3. Chlorophyll fluorescence parameters of the plant leaves for the lettuce type Lollo Rosso, variety Tuska in an unheated greenhouse, averaged for the period 2018-2020 year

\begin{tabular}{|c|c|c|c|c|c|c|c|}
\hline & Control & & NPK & Italpollina & Arkobaleno & $\mathrm{LC}$ & Ekoprop \\
\hline $\mathrm{f}_{0}$ & 4699 & & 4894 & 3864 & 4702 & 4862 & 4396 \\
\hline $\mathrm{f}_{0}$ & 3448 & & 3972 & 4017 & 3464 & 3260 & 3939 \\
\hline \multirow[t]{2}{*}{$f_{0}$} & 4966 & & 4022 & 4115 & 3340 & 3717 & 4241 \\
\hline & 4370.8 & & $4295.9^{\text {n.s. }}$ & $3998.4 * *$ & $3835.6 * * *$ & $3946.2 * * *$ & 4192.1 ${ }^{\text {n.s }}$ \\
\hline $\mathrm{Qy}=\mathrm{Fv} / \mathrm{Fm}$ & 0,747 & & 0,772 & 0,760 & 0,773 & 0,757 & 0,763 \\
\hline $\mathrm{Qy}=\mathrm{Fv} / \mathrm{Fm}$ & 0,767 & & 0,792 & 0,770 & 0,775 & 0,783 & 0,780 \\
\hline \multirow[t]{2}{*}{$\mathrm{Qy}=\mathrm{Fv} / \mathrm{Fm}$} & 0,790 & & 0,830 & 0,800 & 0,810 & 0,797 & 0,807 \\
\hline & 0.768 & & $0.798 * *$ & $\mathbf{0 . 7 7 7} * *$ & $0.786 * *$ & $0.779 * *$ & $0.783 * * *$ \\
\hline PAR & 235 & & 271 & 274 & 286 & 173 & 189 \\
\hline PAR & 249 & & 245 & 238 & 365 & 300 & 325 \\
\hline \multirow[t]{2}{*}{ PAR } & 130 & & 124 & 125 & 138 & 131 & 145 \\
\hline & 204.7 & & $213.4^{\text {n.s. }}$ & $212.3^{\text {n.s. }}$ & $263.1 * * *$ & $201.4^{\text {n.s. }}$ & $219.6^{\text {n.s. }}$ \\
\hline LSD & & $\mathrm{F}_{0}$ & Qy & PAR & & & \\
\hline $\mathrm{p}=0.05^{*}$ & & 227.2 & 0.0067 & 17.2 & & & \\
\hline $\mathrm{p}=0.01^{* *}$ & & 304.0 & 0.0090 & 22.9 & & & \\
\hline $\mathrm{p}=0.001^{* * *}$ & & 399.2 & 0.0118 & 30.1 & & & \\
\hline
\end{tabular}

n.s.-no significance difference 
Table 4. Chlorophyll content index (CCI) of the leaves for the lettuce type Lollo Rosso, variety Tuska in an unheated greenhouse averaged for the period 2018-2020 year

\begin{tabular}{|l|c|c|c|c|c|c|}
\hline $\begin{array}{l}\text { date of } \\
\text { estimate }\end{array}$ & Control & NPK & Italpollina & Arkobaleno & LC & Ekoprop \\
\hline fisrt measurement & 2.87 & 3.03 & 2.57 & 2.96 & 3.47 & 3.77 \\
\hline second measurement & 2.93 & 3.00 & 3.10 & 3.25 & 3.80 & 3.50 \\
\hline third measurement & 2.83 & 2.80 & 3.18 & 3.00 & 3.40 & 3.58 \\
\hline mean value & $\mathbf{2 . 8 8}$ & $\mathbf{2 . 9 4}$ n.s. & $\mathbf{2 . 9 5}$ n.s. & $\mathbf{3 . 0 7}^{*}$ & $\mathbf{3 . 5 6}^{* * *}$ & $\mathbf{3 . 6 1}$ \\
\hline
\end{tabular}

\section{LSD}

$\begin{array}{ll}\mathrm{p}=0.05^{*} & 0.16 \\ \mathrm{p}=0.01 * * & 0.22 \\ \mathrm{p}=0.001 * * * & 0.29\end{array}$

n.s.-no significant difference

In parallel with the readings of some indicators of the chlorophyll fluorescence of the leaves, the chlorophyll index - Chlorophyll Content Index (CCI) was measured (Table 4). The lowest mean CCI value was estimated for the non-fertilized control variant, with few exceptions this dependence being maintained for all three dates of measurement. With the exception of the variant Italpolina and the mineral fertilization variant in the other fertilization variants the CCI has a statistically significant higher average value compared to the control variant. The leaves of the variants fertilized by organic and biofertilizers Lumbricompost (LC) and Ekoprop have the highest CCI. The values of the chlorophyll index are in a positive correlation with the values of the quantum yield-Qy, which proves the inducing effect of the organic and biofertilizers on the photosynthetic activity of the plants. The highest average value of fresh mass of the plants, fertilized by Ekoprop, correlated positively with the reported indicator Qy of the chlorophyll fluorescence and higher chlorophyll content index.

\subsection{Vegetative and morphological behavior}

Lollo Rosso type plants are characterized by a slower rate of growth and development and form a smaller vegetative mass, which can also be seen from the measurements of the Tuska variety. At the moment of their first measurement, the plants had formed a relatively smaller number of leaves (Table 5). The plants, fertilized with Ekoprop had the highest number of leaves - 27.16, followed by Arcobaleno with 26.58. The other variants formed between 23.37 and 25.50 leaves. Relatively small differences were reported in the diameter of their rosette. It was the largest for the mineral fertilization variant and for Lumbricompost 34.79 and $34.61 \mathrm{~cm}$, respectively. The variants with organic and biofertilization had formed a rosette with a diameter between 33.65 and $34.79 \mathrm{~cm}$.

Larger differences were observed with the indicators of the stem. The highest mass value had the stem with the Lumbricompost variant of fertilization - $19.53 \mathrm{~g}$, followed by the resulting stem in the case of using Ekoprop - $16.27 \mathrm{~g}$. With the smallest mass of the stem were the unfertilized plants and Arkobaleno, 13.36 and $13.97 \mathrm{~g}$, respectively.

The differences in diameter were significant. It was the largest with Lumbrikompost - fertilization - 18.05 $\mathrm{mm}$ and with Ekoprop- $17.33 \mathrm{~mm}$.

The fresh mass of the whole plant was relatively low, meeting the market requirements, though. The largest mass was formed after organic fertilization with Italpolina and Arkobaleno - between $252.96 \mathrm{~g}$ and $274.87 \mathrm{~g}$. The other variants with organic fertilization yield in fresh mass up to $29.87 \mathrm{~g}$.

The second reading revealed that the plants had continued to grow, albeit slowly (Table 5). There were small differences between the variants of fertilization in the diameter of the plant rosette. It ranged from 32.73 $\mathrm{mm}$ for the control variant (no fertilization) to $36.78 \mathrm{~mm}$ for the variant of fertilization with Ekoprop. The values of the stem indicators were equalized. The diameter of the stem ranged from $15.52 \mathrm{~mm}$ for the control variant (no fertilization) to $18.59 \mathrm{~mm}$ for the variant of fertilization with Ekoprop. The mass of the stem showed greater differences between the variants. It was slightly higher for Ekoprop, Italpolina and Lumbrikompost fertilization, namely: $20.94 \mathrm{~g}, 20.63 \mathrm{~g}$ and $19.60 \mathrm{~g}$ respectively. The fresh mass of the whole plant had increased compared to the previous moment of measurement. The largest were the plants, fertilized with Arkobaleno - $308.87 \mathrm{~g}$. The variants fertilized with organic and biofertilizers - Italpolina, Lumbricompost and Ekoprop - were close in value to conventional fertilization and ranged from $256.62 \mathrm{~g}$ to $295.73 \mathrm{~g}$.

Plant growth was registered at the moment of the third harvest (Table 5). New leaves had been formed in all variants of fertilization, ranging from 3.22 after the control variant (no fertilization) to 5.06 after fertilization with Lumbricompost. The total number of leaves was 
between 27.74 for the unfertilized plants to 32.15 for the ones, fertilized with Ekoprop. Leaf growth was also registered, which caused the formation of a larger leaf rosette, with a diameter, ranging from $34.83 \mathrm{~mm}$ to $40.43 \mathrm{~mm}$.

In most variants, the diameter of the stem had increased significantly, while its mass had grown less. The plants with mineral fertilization had the largest mass - $26.33 \mathrm{~g}$, while the ones, fertilized with Ekoprop and Lumbricompost were with a mass of 21.86 and $21.29 \mathrm{~g}$. This trend is valid for the diameter as well, with
Italpolina and Lumbricompost fertilized plants having the largest diameters. The diameter had increased by $2-4$ $\mathrm{mm}$, but the differences between the variants were insignificant - 1-2 $\mathrm{mm}$.

The fresh mass of the whole plant had also increased slightly. The largest were the plants, fertilized with Ekoprop - $401.74 \mathrm{~g}$, exceeding the mineral fertilized ones by $55.95 \mathrm{ng}$. The other variants with organic fertilization were similar in size to conventional fertilization.

Table 5. Vegetative and morphological behavior of the lettuce type Lollo Rosso, variety Tuska, averaged for the period 2018-2020 year

\begin{tabular}{|c|c|c|c|c|c|c|c|c|}
\hline \multicolumn{2}{|l|}{ Index } & Variant & Control & NPK & Italpollina & \multirow{2}{*}{\begin{tabular}{c|c} 
Arkobaleno \\
34.42
\end{tabular}} & \multirow{2}{*}{$\begin{array}{l}\mathbf{L C} \\
34.61\end{array}$} & \multirow{2}{*}{$\begin{array}{c}\text { Ekoprop NX } \\
33.65\end{array}$} \\
\hline \multirow{3}{*}{\multicolumn{2}{|c|}{$\begin{array}{l}\text { leaf rosette } \\
\text { diameter, } \\
\text { cm }\end{array}$}} & fisrt measurement & 30.18 & 34.79 & 33.77 & & & \\
\hline & & second measurement & 32.73 & 32.92 & 35.17 & 34.94 & 35.58 & 36.78 \\
\hline & & third measurement & 34.83 & 40.12 & 38.77 & 38.75 & 40.43 & 38.92 \\
\hline \multicolumn{2}{|c|}{ LSD } & \multirow{4}{*}{ average } & \multirow{4}{*}{32.59} & \multirow{4}{*}{$35.94 * * *$} & \multirow{4}{*}{$35.90 * * *$} & \multirow{4}{*}{$36.04 * * *$} & \multirow{4}{*}{$36.87 * * *$} & \multirow{4}{*}{$36.45 * * *$} \\
\hline$p=0.05^{*}$ & 1.43 & & & & & & & \\
\hline $\mathrm{p}=0.01 * *$ & 1.89 & & & & & & & \\
\hline $\mathbf{p}=0.001 * * *$ & 2.43 & & & & & & & \\
\hline \multirow{3}{*}{\multicolumn{2}{|c|}{$\begin{array}{l}\text { stem mass, } \\
\mathrm{g}\end{array}$}} & fisrt measurement & 13.36 & 14.4 & 14.82 & 13.97 & 19.53 & 16.27 \\
\hline & & second measurement & 16.98 & 18.54 & 20.63 & 19.46 & 19.6 & 20.94 \\
\hline & & third measurement & 19.4 & 26.33 & 21.08 & 19.71 & 21.29 & 21.86 \\
\hline LSI & & \multirow{4}{*}{ average } & \multirow{4}{*}{16.58} & \multirow{4}{*}{$19.76^{*}$} & \multirow{4}{*}{18.84 n.s } & \multirow{4}{*}{$17.71 \mathrm{n} . \mathrm{s}$} & \multirow{4}{*}{$20.14 *$} & \multirow{4}{*}{$19.69 *$} \\
\hline $\mathrm{p}=0.05^{*}$ & 2.78 & & & & & & & \\
\hline $\mathbf{p}=0.01 * *$ & 3.67 & & & & & & & \\
\hline $\mathbf{p}=0.001 * * *$ & 4.74 & & & & & & & \\
\hline \multirow{3}{*}{\multicolumn{2}{|c|}{$\begin{array}{l}\text { stem diameter, } \\
\text { mm }\end{array}$}} & fisrt measurement & 14.80 & 15.37 & 17.00 & 16.81 & 18.05 & 17.33 \\
\hline & & second measurement & 15.52 & 17.6 & 17.10 & 18.35 & 18.45 & 18.59 \\
\hline & & third measurement & 19.53 & 20.59 & 21.81 & 20.49 & 21.69 & 21.49 \\
\hline LSI & & \multirow{4}{*}{ average } & \multirow{4}{*}{16.62} & \multirow{4}{*}{$17.85 *$} & & & & \\
\hline $\mathrm{p}=0.05^{*}$ & 0.90 & & & & & & & \\
\hline $\mathrm{p}=0.01 * *$ & 1.26 & & & & $18.64 * * *$ & $18.55 * * *$ & $19.40 * * *$ & $19.14 * * *$ \\
\hline $\mathbf{p}=0.001 * * *$ & 1.62 & & & & & & & \\
\hline & & fisrt measurement & 23.37 & 25.08 & 25.29 & 26.58 & 25.50 & 27.16 \\
\hline leaves, & & second measurement & 24.52 & 26.33 & 26.79 & 26.92 & 25.87 & 27.67 \\
\hline & & third measurement & 27.74 & 29.96 & 30.04 & 30.62 & 30.93 & 32.15 \\
\hline LSI & & & & & & & & \\
\hline $\mathrm{p}=0.05^{*}$ & 1.43 & average & 25.22 & 27.12* & $27.3 * *$ & $28.04 * * *$ & $27.44 * *$ & $29.00 * * *$ \\
\hline $\begin{array}{l}\mathbf{p}=0.01 * * \\
\mathbf{p}=0.001 * * *\end{array}$ & $\begin{array}{l}1.90 \\
2.45\end{array}$ & average & 25.22 & $27.12^{*}$ & 27.5 & 28.04 & 21.44 & 29.00 \\
\hline & & fisrt measurement & 231.38 & 274.87 & 255.50 & 252.96 & 245.17 & 249.97 \\
\hline $\begin{array}{l}\text { fresh mass } \\
\text { of the whole }\end{array}$ & ant, $g$ & second measurement & 250.62 & 287.04 & 295.73 & 308.87 & 256.62 & 273.75 \\
\hline & & third measurement & 331.29 & 345.79 & 348.67 & 362.04 & 377.59 & 401.74 \\
\hline LSI & & & & & & & & \\
\hline $\mathrm{p}=0.05^{*}$ & 34.01 & ovoroc & 27110 & $30057 \mathrm{~ns}$ & $20007 \mathrm{n}$ & $30706 *$ & $20313 n s$ & $30840 *$ \\
\hline $\mathrm{p}=0.01 * *$ & 48.94 & average & 271.10 & $302.5 /$ n.s. & & & 295.15n.s. & \\
\hline $\mathbf{p}=0.001 * * *$ & 63.10 & & & & & & & \\
\hline
\end{tabular}




\section{Conclusions}

1. The most optimal ratio between PAR and Qy is reported for the variants of using the organic and biofertilizers Ekoprop and Arkobaleno, as well as with the mineral fertilizer.

2. The leaves in the variants of fertilization with the organic and biofertilizers Lumbricompost (LC) and Ekoprop have the highest CCI.

3. In fertilization with organic fertilizers the values of the chlorophyll index are in a positive correlation with the values of the quantum yield-Qy, which proves the inducing effect of their usage on the photosynthetic activity of the plants.

4. Organic fertilizers are able to meet the need for essential nutrients when growing lettuce in polyethylene greenhouses and outdoors. All variants fertilized with organic and biofertilizers comply with the quality standard from the beginning to the end of harvesting. The variants fertilized with organic and biofertilizers form plants close in their average mass to those, grown after conventional fertilization with mineral fertilizers, and at the end of the harvest the plants grown after biological fertilization with Ekoprop surpass it.

5. Under the same meteorological conditions, organically fertilized plants have more adequate physiological responses and resistance than conventionally grown ones. 6 . The use of biological technologies for growing lettuce in urban areas (urban conditions, environment) protects the environment, the soil and human health without compromising its quality.

Acknowledgements: This research was supported by Bulgarian National Science Fund grand.

\section{References}

1. H. G. W. Fogg, Salad crops all year round. UK: Newton Abbot 200 pages (1983)

2. T. Marinova, K. Malcheva, L. Bocheva, L. Trifonova, Climate profile of Bulgaria in the period 1988-2016 and brief climatic assessment of 2017. Bul. J. Meteo \& Hydro 22/3-4 (2017): 2-15 (2017)

3. V. Alexandrov, M Schneider, E. Koleva, J. M. Moisselin, Climate variability and change in Bulgaria during the 20th century. Theoretical and Applied Climatology, 79, 3-4, Springer 133-149 (2004)

4. V. Georgieva, V. Kazandjiev, A. Stoycheva, Assessment of agroclimatic conditions in Plovdiv district. - In: International conference, 135 Years Agricultural science in Sadovo and 40 Years Institute of Plant Genetic Resources-Sadovo": 547564 (2017)

5. Z. Popova, M. Ivanova, D. Martins, L.S. Pereira, K. Doneva, V. Alexandrov, M. Kercheva, Vulnerability of Bulgarian agriculture to drought and climate variability with focus on rainfed maize systems. Natural Hazards, 74, 2, Springer, 865-886 (2014)

6. N. Shopova, D. Cholakov, Effect of the age and planting area of tomato (Solanum licopersicum L.) seedlings for late field production on the physiological behavior of plants. Bulgarian Journal of Agricultural Science, 20 (No 1), 173-177 (2014)

7. S. Mathur, D. Agrawal, A. Jajoo, Photosynthesis: Responses to High Temperature Stress. Journal of Photochemistry and Photobiology, 137,116-26 (2014)

8. H. M. Kalaji, A. Jajoo, A. Oukarroum, M. Brectic, M. Zivcak, I. Saqmborska, M. Centner, I. Lakazik, V. Goltsev, R. Ladle, Chlorophyll a Fluorescence as a Tool to Monitor Physiological Status of Plants under Abiotic Stress Conditions." Acta Physiologiae Plantarum, 38, 102-25 (2016).

9. E. Murchie, T. Lawson, Chlorophyll fluorescence analysis: a guide to good practice and understanding some new applications. Journal of Experimental Botany, 64 (13), 3983-3998 (2013)

10. K. Roháček, Chlorophyll fluorescence parameters: the definitions, photosynthetic meaning, and mutual relationships. Photosynthetica, 40, 13-29 (2002)

11. A. Ferrante, T. Maggiore, Chlorophyll a fluorescence measurements to evaluate storage time and temperature of Valeriana leafy vegetables. Postharvest Biology and Technology, Volume 45, Issue 1, July 2007, Pages 73-80 (2007)

12. R. A. Schofiled, J.R. De Ell, D.P. Murr, S. Jenni, Determining the storage potential (2005)

13. Opti-Sciences, Inc., CCM-200 Chlorophyll Content Meter. http://www.optisci.com/ccm.htm (2002)

14. A. D. Richardson, S. Duigan, G. Berlyn, An evaluation of noninvasive methods to estimate foliar chlorophyll content. New Phytologist, 153,185-194 (2002)

15. V. Valcheva, K. Trendafilov, M. Almaliev, Nitrogen mineralization potential of alluvial-meadow soil after long-term fertilization, Agricultural science and technology, vol.7, No 4, 476-480, (2015)

16. K. P. Kostadinov \& S. V. Filipov, Effect of Composition of Mixture on Reproductive Manifestations in Greenhouse Tomato. New Knowledge Journal of Science / Novo Znanie . Dec2013, Vol. 2 Issue 4, 104-110 (2013)

17. Gide to Agricultural Meteorological Practices. WMO, No.134, Ch. 6-39 (2011)

18. K. Maxwell, G.N. Johnson, Chlorophyll fluorescence a practical guide. Journal of Experimental Botany, 51(345), 659-668 (2000)

19. L. Nedbal, J. Soukupová, D. Kaftan, J. Whitmarsh, M. Trtílek, Kinetic imaging of chlorophyll fluorescence using modulated light. Photosynthesis Research, 66, 3-12.

20. P. I. Kartalov, M. P. Doykova, P. Boshnakov, Vegetable production with seed production. Sofia: Videnov and son, p. 305 (1999) 
21. O.A. Lorenz and D.N. Maynard, Knott's Handbook for Vegetable Growers. 3rd Edition, Jhon Wiley \& Sons, Inc., Hoboken, p. 456 (1988)

22. O. Lorenz \& Maynard DM (2007). Knott's handbook for vegetable growers. John Wiley and Sons, New York

23. L. Morgan, Introduction. Hydroponic lettuce production. Australia: Casper Publications Pty Ltd (1999)

24. T. D. Cholakov, Vegetable production Plovdiv. Academic Publishing House of the Agrarian University, p. 283 (1999)

25. S. Kristensen, E. Friis, K. Henriksen and S. A. Mikkelsen, Application of temperature sums in the timing of production of crisp lettuce. Acta Horticulturae, 198, 217-225 (1987)

26. L. Morgan, Introduction. Hydroponic lettuce production. Australia: Casper Publications Pty Ltd (1999)

27. U. Meier (ed.), (Feller et al., 1995 a), Growth stages of mono-and dicotyledonous plants $\mathrm{BBCH}$ Monograph Edition, 118-126 (2001)

28. Z. Zlatev, T. Kolev, Changes in chlorophyll fluorescence and leaf gas exchange of durum wheat under low positive temperatures. Agricultural science and technology, 4(1), 20-23 (2012)

29. J. Chen, J. Burke, Z. Xin, Chlorophyll fluorescence analysis revealed essential roles of FtsH11 protease in regulation of the adaptive responses of photosynthetic systems to high temperature. BMC Plant Biology, 1-13 (2018) Springer 133-149 (2004)

30. B. Demmig, O. Björkman, Photon yield of O2 evolution and chlorophyll fluorescence Characteristics at $77 \mathrm{~K}$ among vascular plants of diverse origins. Planta, 170, 489-504 (1987) 